period, $0.05 \mathrm{ml}$. of piperidine and $0.25 \mathrm{ml}$. of acetic acid were added. The product was subjected directly to distillation under $0.05 \mathrm{~mm}$. pressure. The ester (I) boiled at $160-162^{\circ}$ and formed a colourless oil ; yield, $12 \mathrm{gm}$. (40 per cent).

Analysis: Calculated for $\mathrm{C}_{13} \mathrm{H}_{16} \mathrm{NO}_{6} \mathrm{~F}: \mathrm{C}, 51 \cdot 8$; $\mathrm{H}, \mathbf{5} \cdot 3 ; \mathrm{N}, 4 \cdot 7 ; \mathrm{F}, \mathbf{6} \cdot \mathbf{3}$.

Found: $\mathrm{C}, 51 \cdot 5 ; \mathrm{H}, 5 \cdot 6$; N, 4.3 ; $\mathrm{F}, 5 \cdot 9$.

Triethyl $\alpha$-fluoroaconitate $(I I)$. A mixture of $5 \mathrm{gm}$. of concentrated sulphuric acid and $1 \mathrm{gm}$. of water was added to a solution of $12 \mathrm{gm}$. of (I) in $20 \mathrm{ml}$. of anhydrous alcohol, refluxed for $5 \mathrm{hr}$. and poured into cold 10 per cent sodium hydrogen carbonate solution. Extraction with ether, drying and distillation gave $5 \mathrm{gm}$. (45 per cent) of triethyl $\alpha$-fluoroaconitate (II), b.p. $115-117^{\circ}(0 \cdot 1 \mathrm{~mm}$. $)$.

Analysis: Calculated for $\mathrm{C}_{12} \mathrm{H}_{17} \mathrm{FO}_{6}: \mathrm{C}, 52 \cdot 2$; $\mathrm{H}, 6 \cdot 2 ; \mathrm{F}, 6 \cdot 9$.

Found : C, $52 \cdot 4 ; \mathrm{H}, 6 \cdot 3 ; \mathrm{F}, 6 \cdot 5$.

This work was sponsored by the U.S. National Institutes of Health.

Ernst D. Bergmann I. SHAHAK

Department of Organic Chemistry, Hebrew University, Jerusalem.

${ }^{1}$ Peters, R. A., “Adv. in Enzymol.", 18, 13 (Interscience Pub. Inc. New York, 1957).

${ }^{2}$ Rivett, D. E. A., J. Chem. Soe., 3710 (1953).

${ }^{3}$ Kacser, H., Discuss. Farad. Soc., 20, 289 (1955).

${ }^{4}$ Blank, I. Mager, J., and Bergmann, E. D., Bull. Res. Council Israel, 3, 101 (1953); J. Chem. Soc., 2180 (1955).

\section{Colorimetric Determination of Amino-acid Concentration}

A VERSATILE method of amino-acid determination is that in which amino-acid solutions are incubated with eupric orthophosphate in suspension. The resulting solution contains copper in proportion to the total molarity of amino-acids and the copper is determined by any suitable method. The methods used have included iodometric titration ${ }^{1}$ and the use of cupric phosphate labelled with copper-64 followed by the determination of the activity in the supernatant ${ }^{2}$. The latter method is of particular use for the continuous determination of amino-acids in chromatographic eluates.

I have determined the copper colorimetrically using sodium diethyl dithio carbamate as the copper reagent. The colour produced is stable and has a maximum absorption at $440 \mu$. The stages in the procedure are as follows.

(1) $0.1 \mathrm{ml}$. of the sample, $3.0 \mathrm{ml}$. of cupric orthophosphate suspension (l per cent aq.), $2 \cdot 0 \mathrm{ml}$. of B.D.H. Universal buffer solution, $p \mathrm{H}_{7 \cdot 0^{3}}$ are incubated overnight in a centrifuge tube. A reagent blank is used with distilled water replacing the sample. Using finely divided cupric orthophosphate (B.D.H.) shaking was found to be unnecessary even when using conical centrifuge tubes, the recovery figures being identical in procedures with and without shaking. The tubes are centrifuged to sediment the cupric orthophosphate and a part of the supernatant withdrawn for colour development.

(2) $0.1 \mathrm{ml}$. of the supernatant from (1), $3.0 \mathrm{ml}$. of B.D.H. Universal buffer $p \mathrm{H} .7 \cdot 0,0 \cdot 1 \mathrm{ml}$. of sodium diethyl dithio carbamate 1.0 per cent aq., are mixed at room temperature. The optical density at $440 \mu$ does not increase after $15 \mathrm{~min}$. from mixing, and is read at any convenient time, being stable for at least
$24 \mathrm{hr} . \quad$ A 'Unicam' S.P. 500 or similar instrument is used with a violet filter. If the colour is too dense or if precipitation occurs, the supernatant from stage (1) is diluted and stage (2) repeated. The results obtained show that, due to the large excess of cupric orthophosphate in stage (1), the relationship [copper]/[amino-acid] is linear over a wide range, so that dilution is permissible with no inherent inaccuracy. The 'recovery' of added amino-acids was 100 per cent \pm 2 per cent over a concentration range of $50-1,000 \mu \mathrm{gm} . / \mathrm{ml}$. $\alpha$-alanine. This method has proved to be useful in enzyme kinetic work.

Nielsen ${ }^{4}$ describes the estimation of proteins by a related method, involving the removal of amino-acids before reaction of the proteins and trichloracetic acid-insoluble peptides with cupric sulphate. Excess copper is removed by precipitation as cupric orthophosphate and the copper in solution as a peptide complex is estimated using diethyl dithio carbamic acid. In the method here described, peptides and proteins are found not to give any appreciable copper uptake from cupric orthophosphate, the results for amino-acid concentration obtained from solutions containing amino-acids, peptides and proteins being within 2 per cent of those obtained by formol titration and by the Folin-Ciocalteau method ${ }^{5}$.

W. A. VINCENT

Department of Biological Sciences, Institute of rTechnology, Bradford, 7.

${ }^{1}$ Pope, C. G., and Stevens, M. F., Biochem. J., 33, 1070 (1939), ${ }^{2}$ Blackburn, S., and Robson, A., Biochem. J., 54, 295 (1953).

3 Prideaux, E. B. R., and Ward, A. T., J. Chem. Soc., 125, 426 (1924). "Nielsen, H., Acta Chem. Scand., 12, 1, 38 (1958).

"Wallenfels, K., Biochem. Z., 321, 189 (1950).

\section{BIOCHEMISTRY}

\section{Volatile Amines in Brain}

WE have reported previously the isolation and identification of the volatile amine 2-dimethylaminoethanol in the brain of man and pig and in other biological material ${ }^{1,2}$. Bremer and Greenberg's ${ }^{3}$ report on its presence in rat-liver phospholipids has substantiated our findings. During our investigation several volatile amines-besides the previously identified volatile bases ammonia ${ }^{4}$ and 2 -amino. ethanol ${ }^{5}$-were isolated from brain tissue and we became interested in analysing the brain for other normally occurring volatile amines.

Brain tissues from cat, pig and man, processed 1 , 30 and $360 \mathrm{~min}$. after death, respectively, were used. The extraction was carried out by three different methods to get a more accurate picture of the amines present. Accordingly, the tissue was extracted 3-4 times with either 80 per cent ethanol, adjusted to $p \mathrm{H} 2$ with hydrochloric acid (EtOH-HCl), as described earlier ${ }^{2}$; or with acetone followed by 80 per cent ethanol (acetone-EtOH); or with 5 per cent trichloracetic acid. The supernatant contained the unbound or free amines; the precipitate, the bound amines. Since we were primarily interested in the unbound amine content of the brain, most of the following procedures involved only the supernatant fractions. In the case of the trichloracetic acid treatment the aqueous solution was extracted with ether and passed through an anion exchange column ('Dowex 2', Cl-form), in order to remove the trichloracetic acid. The supernatants were individually concentrated in 